\title{
Effect of a Training Program Using Bands on Strength and Speed of Straight Punches Delivery and Electric Activity of Some Muscles
}

\section{"Dr/ Essam Ahmed Helmy Mohamed AbouGamil ,}

\section{Introduction}

Bands is form the best tools which can be used for improving the athlete's level of strength in all its elements, Since they provide two main advantages which aren't available in the traditional strength exercises .

The first advantage as each of (AbouGamil, E. A. 2015) , (Aboodara, S. J., et. al.2011) , (Saied, J.A., et. al. 2011), (Thibaudeau , C. 2007) indicates is that the resistance level which muscles working against during exercise performance gets more higher as the movement proceeds from its beginning to its end, because the higher degree of the band extension the greater degree of the resistance will be , which summons the greater degree of muscle contraction . This fits with the nature of muscle contractions during the performance of various sports movements, Where the athlete can be more capable to exert strength as the central movement gets more closer to its end, Thus the purpose of the exercise can be achieved with more effectiveness than traditional exercises . (2) , $(3: 231),(25),(28: 34,80)$.

The second advantage as each of (AbouGamil, E. A. 2015), (Thomas, R. B. 2008), (Thibaudeau, C. 2007) indicates is that the performance of strength exercises by the using of bands doesn't include the need to slow down the central movement of the exercise during at least its latter one third as in the traditional strength exercises, which have to be done to reduce the negative impact of the inertia of the moving used weight as it swings during the exercise performance to avoid causing a shock for the configuration of the participated body joints in

"Athletic Training and Kinesiology Department, Physical Education Faculty for Young Men and Girls, Port Said University

Assiut Journal For Sport Science Arts 
the movement, and this reduces the effectiveness of the traditional strength exercise of achieving its purpose during this part of the movement, while this part is the most influential part of the movement to perform sports skills successfully through various sports competitions . $(3: 231),(28: 34,79),(29: 471-$ 491)

In addition to the previous two advantages of strength exercises with using bands to develop strength for athletes there is one more special advantage for boxers, that is the resistance nature which used in theses exercises focused in the direction of the movement, and doesn't include any heading down resistance as a result of the Earth's gravity on the weights which used in traditional strength exercises .

But strength exercises by the using of bands for boxers may adversely affect the speed of the punches delivery, Because the getting higher of exercise resistance as the movement getting closer to its end may cause also more disability to exert speed for muscle contraction .

Strength and speed of punches delivery occupy a paramount importance for boxers to achieve the best results, especially the straight punches as referred to by both of (Osman, I. H. \& ghoneim, M. A. \& El-azab, D. M. 1997), (Khedr, A. F. 1996), (Mohamed, A. A. 1995), (Elazab, D. M. 1994), (Shalan, A. M. \& Ghoneim, M. A. 1990) that the straight punches are the most used punches during the boxing championships . (11), (17:141), (20), (22:98), (26) .

The possible changes which caused by strength exercises with the using of bands in the electrical activity of the muscles compared with these changes which caused by traditional strength exercises aren't known, so it's best to know these changes to stand on some physiological reasons of any changes in the strength and the speed of punches delivery as a result of the using of the bands in strength exercises for boxers .

Finally from all already mentioned above, the problem of the research can be limited in finding the effect of using the bands in strength training for boxers on each of strength and speed of straight punches 
delivery, and the muscle electric activity of the most important working muscles during these Punches .

\section{Objectives :}

1- Identify the effect of a training program using bands on the strength of the right and left straight punch .

2- Identify the effect of a training program using bands on the speed of punches delivery .

3- Identify the effect of a training program using bands of the most important working muscles during bunches delivery.

\section{Procedures :}

\section{- The Method}

The researcher used the experimental method by using of per - post measurements of two groups, one was the control group and the other was the experimental group, each group consisted of six boxers .

\section{- The Samples}

Pilot and main groups were selected purposely from boxers of the youth center of Port fouad and the Port Fouad Club , which were Registered in the Egyptian Federation of Boxing , at the age of 18-20 years . Pilot sample consisted of 10 boxers from youth center of Port Fouad, while the main sample consisted of 12 boxers from Port Fouad Club and was divided into two groups, one was the control group and the other was the experimental group .

Table (1) shows the characteristics of each of the sample of the pilot study and the main sample of the research in the main variables (age, height, weight and training age), and the variables of the strength of the straight punch delivery [St.spd] (left \& right), and the speed of the straight punches delivery [Sp.spd] . 
Table (1)

the characteristics of the sample of the pilot study and the main sample of the research in the main variables and the variables of the strength and the speed of punches delivery

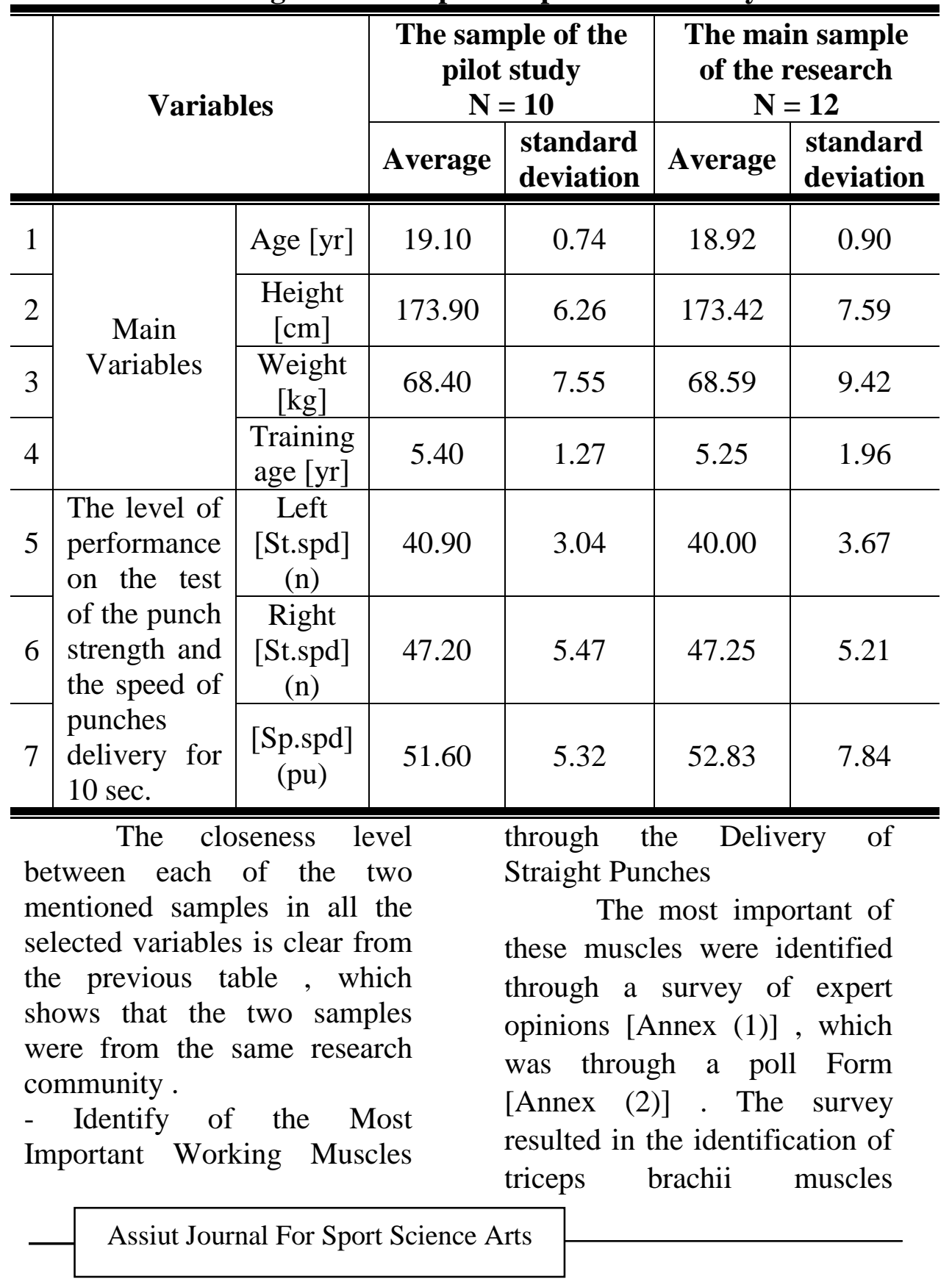


(T.B.M) , the deltoid muscles (D.M.), and the pectoralis major muscles (P.M.M.) as the most important working muscles through the delivery of the straight punches .

- Determining of the Validity of the Used Tests in Measuring the subsidiary variables

The researcher used the logical validity to determine the validity of these tests by polling some experts [Annex (1)], which was through a poll form [Annex (2)] about the validity of these tests in measuring the subsidiary variables, the researcher used the punch force test by using of the device of measuring the punch force which had been used in the researches of (Abdullah, H.M. 2012) , (Khalifa , M.A. 1997) (1) , (16) [Annex No. (3)] to measure the two variables of left \& right (St.spd) , the researcher also used the test of the speed of punches delivery for $10 \mathrm{sec}$. which had been used in the research of (ElHoala, E.A. 2006) (12) [Annex No. (4)] to measure the variable of (Sp.spd), and the researcher also used the test of electrical activity of muscles (M.E.A.) by using of electromyography (EMG) device of Faculty of Physical Education in Port Said [Annex No. (5)] to measure the variables of (M.E.A) of muscles under the research .

All of the experts unanimous on the validity of those tests, thus the value of the coefficients of all those tests were (1 integer) .

\section{- The Pilot Study}

It was conducted on $05 / 30,06 / 02$ / 2015 on its sample, in order to identify the stability coefficients of the tests of the strength and the speed of punches delivery . Test re-test method was used with two days between the two applications to calculate the stability coefficients .

The following table shows each of the first and the second application data on the sample of the pilot study and the data of calculating the stability coefficients. 
Table (2)

Data of calculating the stability coefficients of the strength of the punches delivery test and the speed of punches delivery test for 10 sec. $(\mathbf{N}=10)$

\begin{tabular}{|c|c|c|c|c|c|c|c|}
\hline \multirow{2}{*}{\multicolumn{2}{|c|}{ Data }} & \multicolumn{2}{|c|}{$\begin{array}{l}\text { The first } \\
\text { Application }\end{array}$} & \multicolumn{2}{|c|}{$\begin{array}{l}\text { The second } \\
\text { application }\end{array}$} & \multirow{2}{*}{$\begin{array}{c}\text { The } \\
\text { difference } \\
\text { between the } \\
\text { two } \\
\text { applications }\end{array}$} & \multirow{2}{*}{$\begin{array}{l}\text { Stability } \\
\text { coefficient } \\
\quad\left(R_{s}\right)\end{array}$} \\
\hline & & Average & $\begin{array}{l}\text { Standard } \\
\text { deviation }\end{array}$ & Average & $\begin{array}{l}\text { standard } \\
\text { deviation }\end{array}$ & & \\
\hline \multirow{3}{*}{ 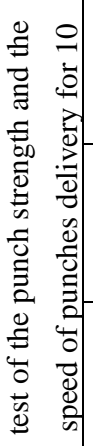 } & $\begin{array}{c}\text { Left } \\
{[\text { St.spd] }} \\
\text { (n) }\end{array}$ & 40.90 & 3.04 & 40.70 & 3.09 & 0.20 & $* * 0.973$ \\
\hline & $\begin{array}{c}\text { Right } \\
\text { [St.spd] } \\
\text { (n) }\end{array}$ & 47.20 & 5.47 & 47.60 & 5.87 & -0.40 & $* * 0.994$ \\
\hline & $\begin{array}{c}\text { [Sp.spd] } \\
(\mathrm{pu})\end{array}$ & 51.60 & 5.32 & 52.40 & 5.06 & -0.80 & $* * 0.967$ \\
\hline
\end{tabular}

Indexed $\left(\mathrm{R}_{\mathrm{s}}\right)$ at the level of $0.01,0.05$ is $0.824,0.648(4: 315),(23: 348)$.

The above table indicates that the stability coefficients of the all mentioned tests were ranged in between 0.973 to 0.994 , thus they are all strong coefficients . - The Design of the Training Program

After reviewing the scientific researches and the references which are specialized in sports training and in boxing sport, the researcher designed the proposed training program on the following bases
- The only difference between the control group and the experimental group in the training program was only the entering of the experimental factor - which was the using of bands in the strength exercises - on the training program for the experimental group .

- The training program was consisted of eleven microcycle - eleven training weeks, and ended before the Republic Championship of Boxing which followed the program application and which came after more than two weeks, to 
give the opportunity for the coach of boxers which the program was applied to them to focus on preparing their boxers and continue the tapering process as commensurate with the individual case of each boxer before their participation in the championship .

- Each micro-cycle training week - included three training units, each of them was in one-day. Thus this training program included thirty three training units, and the time of each one lasted for 90 min. - 120 min. .

- The weekly training units for the control group were on Saturday, Monday and Wednesday, while these units for the experimental group were on Sunday , Tuesday and Thursday .

- Taking into account the rippling in the training load levels through the micro-cycles which were constituent for each stage of the program, by using of the maximum and sub-maximum load in the three training units of the microcycle, while the remaining days of the micro-cycle were dedicated to rest, and that with the exception of the last week of the training program which through training load was gradually reduced in order to the preparation for the postmeasurements .

- All training units of the training program contain strength exercises with weights or bands, except of the last week before the postmeasurement to exclude the negative effects of the fatigue from training with weights or bans on the measurement results as possible.

- Strength exercises to develop any of strength elements for only the control group [Annex (6)] were by using of bands . These exercises was selected according to a poll of experts [Annex (1)] by Using of a poll form [Annex (2)] .

- Taking into account the individual differences in the maximum weight and maximum resistance in the light of periodic measurement of the maximum weight and maximum resistance in each strength exercise was used in the training program for each boxer.

Researcher conducted a poll for some experts [Annex (1)] in regarding of the previous bases and the timetable division of the 
program periods through a poll form of experts [Annex (2)] . Some adjustments were made in the light of their opinions . In the annexes there is an annex shows the timetable distribution of the training trends in the training units of the program [Annex (7)], and there also an annex shows three units form training program units, each of them in one of the three periods of the training program [Annex (8)] .

- The Per-Measurements

The per-measurements were conducted for the persons of the main sample of the research in the period of 6$12 / 6 / 2015$, the researcher conducted the measurements of the main variables (age, height

\section{Table (3)}

Data of the per-measurements of the control \& the experimental groups and statistical significance of the differences between them

$$
\mathrm{N}_{1}=\mathrm{N}_{2}=6
$$

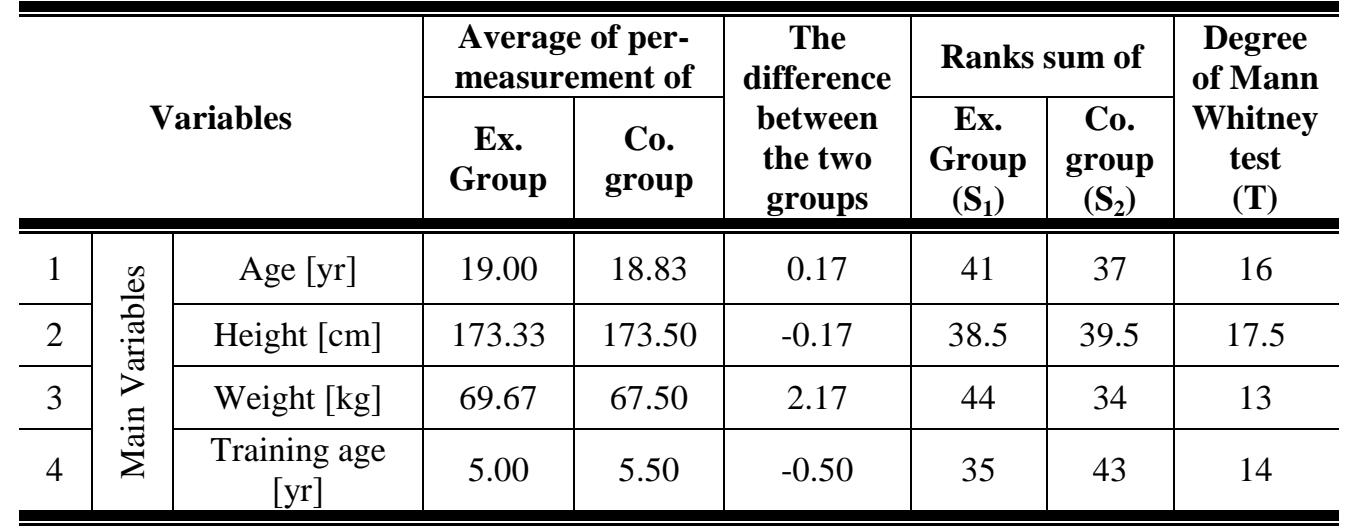

Assiut Journal For Sport Science Arts
, weight , training age) and the subsidiary variables which were the left \& right (St.spd), [Sp.spd] , and (M.E.A.) of the left \& right (T.B.M) , the left \& right (D.M.) and the left \& right (P.M.M.) .

- The Parity between the Two Groups of Research

The parity between the control and experimental groups was made in the previously mentioned variables of the per-measurements . Table (3) shows the results of the per-measurements and the parity between the experimental group (Ex. group) and the control group (co. group) in each of those variables . 
Follow Table (3)

Data of the per-measurements of the control $\&$ the experimental groups and statistical significance of the differences between them $N_{1}=N_{2}=6$

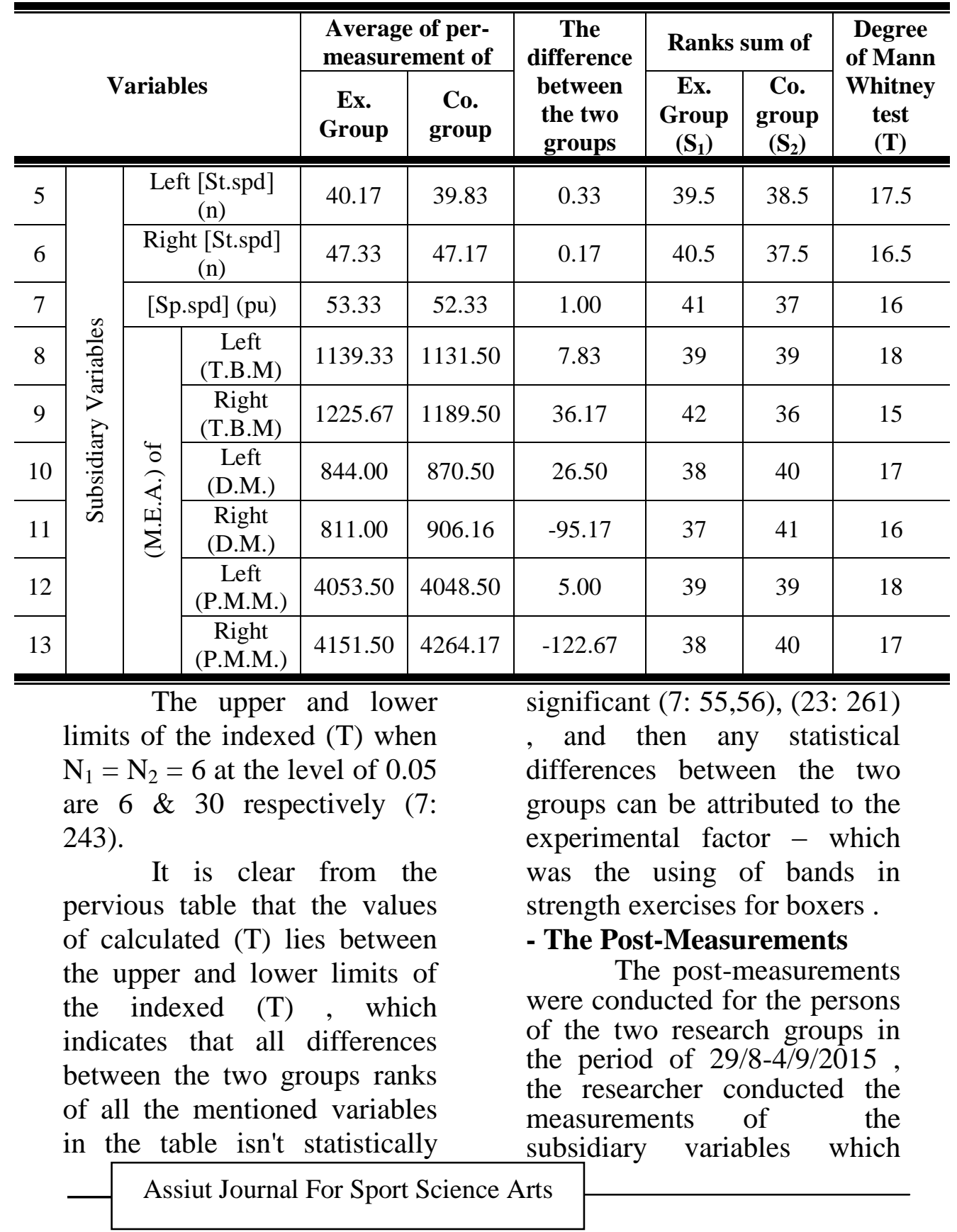


were mentioned before in the per-measurements , and that was after the completion of the application of the proposed training program .

- The Statistical Analysis

The researcher used the Non Parametric Statistics for the treatment of the research data, because the persons number of any of the main or the pilot study of the research was less than 30 person, and this was according to what referred by (Radwan, M.N. 2003) \& (Radwan, M.N.

\section{Table (4)}

Data of the post-measurements of the control \& the experimental groups and statistical significance of the differences between them

$$
N_{1}=N_{2}=6
$$

\begin{tabular}{|c|c|c|c|c|c|c|c|c|}
\hline \multirow{2}{*}{\multicolumn{3}{|c|}{$\begin{array}{c}\text { Subsidiary } \\
\text { Variables }\end{array}$}} & \multicolumn{2}{|c|}{$\begin{array}{l}\text { Average of per- } \\
\text { measurement of }\end{array}$} & \multirow{3}{*}{$\begin{array}{c}\begin{array}{c}\text { The } \\
\text { difference } \\
\text { between } \\
\text { the two } \\
\text { groups }\end{array} \\
-4.33\end{array}$} & \multicolumn{2}{|c|}{ Ranks sum of } & \multirow{3}{*}{$\begin{array}{c}\text { Degree } \\
\text { of Mann } \\
\text { Whitney } \\
\text { test } \\
\text { (T) }\end{array}$} \\
\hline & & & \multirow{2}{*}{$\begin{array}{c}\begin{array}{c}\text { Ex. } \\
\text { Group }\end{array} \\
44.00\end{array}$} & \multirow{2}{*}{$\begin{array}{c}\begin{array}{c}\text { Co. } \\
\text { group }\end{array} \\
48.33\end{array}$} & & \multirow{2}{*}{$\begin{array}{c}\begin{array}{c}\text { Ex. } \\
\text { group } \\
\left(\mathbf{S}_{\mathbf{1}}\right)\end{array} \\
25.50\end{array}$} & \multirow{2}{*}{$\begin{array}{c}\begin{array}{c}\text { Co. } \\
\text { group } \\
\left(\mathbf{S}_{2}\right)\end{array} \\
52.50\end{array}$} & \\
\hline 1 & & St.spd] (n) & & & & & & \\
\hline 2 & \multicolumn{2}{|c|}{ Right [St.spd] (n) } & 48.50 & 56.17 & -7.67 & 25.00 & 53.00 & $* 4.0$ \\
\hline 3 & \multicolumn{2}{|c|}{$[\mathrm{Sp} . \mathrm{spd}](\mathrm{pu})$} & 55.67 & 57.00 & -1.33 & 36.50 & 41.50 & 15.5 \\
\hline 4 & \multirow{6}{*}{ 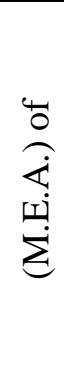 } & $\begin{array}{c}\text { Left } \\
\text { (T.B.M) }\end{array}$ & 1256.67 & 1386.00 & -129.33 & 31.00 & 47.00 & 10 \\
\hline 5 & & $\begin{array}{l}\text { Right } \\
\text { (T.B.M) }\end{array}$ & 1341.50 & 1440.33 & -98.83 & 34.00 & 44.00 & 13 \\
\hline 6 & & Left (D.M.) & 957.83 & 1063.83 & 106.00 & 32 & 46 & 11 \\
\hline 7 & & $\begin{array}{l}\text { Right } \\
\text { (D.M.) }\end{array}$ & 975.83 & 1074.33 & -98.50 & 32 & 46 & 11 \\
\hline 8 & & $\begin{array}{l}\text { Left } \\
\text { (P.M.M.) }\end{array}$ & 4350.67 & 4816.50 & -465.38 & 26 & 52 & $* 5$ \\
\hline 9 & & $\begin{array}{l}\text { Right } \\
\text { (P.M.M.) }\end{array}$ & 4469.33 & 5060.83 & -591.50 & 26 & 52 & $* 5$ \\
\hline \multicolumn{5}{|c|}{$\begin{array}{l}\text { The upper and lower } \\
\text { limits of the indexed }(\mathrm{T}) \text { when }\end{array}$} & \multicolumn{4}{|c|}{$\begin{array}{l}N_{1}=N_{2}=6 \text { at the level of } 0.05 \\
\text { are } 6 \& 30 \text { respectively. }\end{array}$} \\
\hline & \multicolumn{5}{|c|}{ Assiut Journal For Sport Science Arts } & & & \\
\hline
\end{tabular}

1989) . (23: 79 ), (24: 70-82) . The researcher the followed treatments

- Spearman's Rank Correlation Coefficient .

- The Mann-Whitney Test for

\section{- Results and Discussion}

The following table shows the differences between in the post-measurements of the results of all the subsidiary variables . Rank differences . the Ex-group and the Co-group 
It is clear from Table (4) that the values of the calculated (T) came less than the value of the indexed $(\mathrm{T})$ with regard of the Left \& Right [St.spd] and the (M.E.A.) of Left \& Right (P.M.M.) variables , and this proved the statistical significance of the differences between the two groups of these variables $(7: 55,56),(23$ : 261), as it is clear from the table that the differences between the averages of these variables were in favor of the experimental group. So the using of bands in strength exercises for boxers had an advantage on the traditional strength exercises in these variables .

It is also evident from the table that the values of calculated (T) lies between the upper and lower limits of the value of indexed $(\mathrm{T})$ at the mentioned level of statistical significance with regard of the remained variables, which indicates that the differences between the two groups of these variables were not statistically significant (7: 55,56), (23: 261), but the differences between the two groups in all of these variables were in favor of the experimental group, this indicates that the using of bands in strength exercises for boxers may have a positive effect on these variables too higher than the traditional exercises, although this is not a the confirmed impact .

Based on the foregoing, it can be concluded that the using of bands in strength exercises improves [St.spd] , [Sp.spd] and increases (M.E.A.) of the muscles which were under the research, with more effectiveness than the traditional strength exercises , although this effectiveness is not confirmed for the [Sp.spd] and the (M.E.A.) of some muscles which were under the research .

The researcher dues the higher effectiveness of strength exercises with the using of bands to the effectiveness of traditional strength exercises in the developing of [St.spd] and (M.E.A.) to the distinction of strength exercises with using of bands by increasing the degree of resistance which muscles work against through the central movement as the movement progress from its beginning to its end, which summons higher degrees of muscle contraction than those degrees in traditional strength 
exercises, this is agreed with what referred to by (Thibaudeau, C. 2007) (28: 3480), and this trains the neuromuscular system of the athlete to electrically activate in higher degrees to recruit more muscle fibers for achieving higher degrees of strength through punches delivery, this is agreed with the findings of each of (Brandt, M., et.al. 2013), (Kozub, F. M., \& Voorhis, T. 2012), (Rainoldi, A. \& Melchiorri, G. 2011), (Saied, J. A., et. Al. 2011), (Andersen,L. L., et. al.2010), (Colado, J. C., et . al 2010), (Stevenson, M. W. 2010), (Muthusubramanian, J. 2000) (6), (8), (10), (18), (19), (21), (25), (27), and this also agreed with what referred to by (Bstawisy, A. 1999) , (Alawy, M. H. 1990), (Hssanen, M. S. 1987) (5: 94-95) , (9: 149) , (13: 228), but this is different from the findings of each of (Jakubiak, N. \& Saunders, D. 2008), (JUAN, C. C. \& TRAVIS, N. T. 2008) (14), (15) .

The researcher also dues the higher effectiveness of strength exercises with the using of bands to the effectiveness of traditional strength exercises in the developing of [St.spd]although it is not confirmed to the higher effectiveness of strength exercises with using of bands in strength improving and to the higher effectiveness of these exercises in increasing the intensity of the nervous system generating to the nerve signals which stimulate the muscle fibers, this resulted in improving [St.spd], because the high strength and high intensity of organized electrical activity in the direction of the purpose of the movement are considered form the factors which increase the movement speed, this is agreed with what refereed to by (Thibaudeau, C. 2007) (28: 34,80). The researcher dues that also to the distinction of strength exercises with the using of bands by two advantages, the first is that it does not include the need to slow down the central movement of the exercise during its termination as in the traditional strength exercises to avoid causing a shock to the bony composition of the involved joints in the movement, as referred to by (Thibaudeau , C. 2007) (28: $34,80)$, and the second is that those exercises with bands exclude the effect of gravity on 
the used weights in the traditional strength exercises , Those two advantages enabled the boxers of the experimental group to perform each punch quickly from its beginning to end without fearing - a natural subconscious fear - of causing that shock, and to concentrate on performing punches quickly and strongly in the direction of its goal, this is agreed with the findings of (Muthusubramanian, J. 2000) .

\section{* Conclusions}

In the framework of the research and its objectives and the results, it can be concluded the following:

1- Strength exercises with the using of bands are more effective than traditional strength exercises for strength development .

2- Strength exercises with the using of bands are more effective than traditional strength exercises to train neuromuscular system to carry more muscle electric activity in order to exert higher levels of strength .

3- Strength exercises with the using of bands may be more effective than traditional strength exercises for the development of the speed of movement .

\section{* Recommendations}

In the framework of the research community, its objectives, its sample, and in the light of its results, the researcher can recommend the following : -

1- The program of strength training must include the using of bands in order to get better results of strength development .2- It have to kept in mind that the using of bands through strength training increases the electric activity of the muscles, which lead to greater output of strength.

3 - It have to kept in mind that the using of bands through strength training does not adversely affect on the speed of movement, but it may improve it .

\section{References}

1- Abdullah , H. M. : (2012), The Impact of Special Coordinative Exercises on the Effectiveness of Some Punch Combinations for Youngsters , Master Thesis , Physical Education Faculty, Mansoura . 2- Aboodarda, S. J., et. al. : (2011), Two Practical Strategies for Developing Resultant Muscle Torque Production Using Elastic Resistance Device , 5th Kuala Lumpur 
Conference on Biomedical Engineering, Vol. 35 , pp. 241 -244 .

3 - AbouGamil, E. A. : (2015)

, Training of Sports Activities , The Modern Book Center, Cairo .

4 - AbouZied, E. k. : (2002), Basics of Statistics in Physical Education , El-Motheda , Port Said .

5 - Alawy, M. H. : (1990), Science of Sports Training, Dar El-fekr Al-Arabi , Cairo 6 - Andersen, L. L., et . al. ; (2010), Muscle Activation and Perceived Loading during Rehabilitation Exercises : Comparison of Dumbbells and Elastic Resistance , Physical Therapy Journal, Vol. 90 , No. 4 , pp. $538-549$.

7- Ashor, S. K. \& AbouAlfetoh, S.: (1995), Nonparametric Tests, Institute of Statistical Studies and Research, Cairo .

8 - Brandt, M., et . al. ; (2013), Perceived Loading and Muscle Activity during Hip Strengthening Exercises : Comparison of Elastic Resistance and Machine Exercises , International Journal of Sports Physical Therapy, Vol. 8 , No. 6 , pp. $811-819$.
9- Bstawisy, A. : (1999), Foundations and Theories of Sports Training, Dar El-fekr Al-Arabi , Cairo .

10 - Colado, J. C., et . al. ; (2010) , A Comparison of Elastic Tubing and Isotonic Resistance Exercises International Journal of Sports Medicine, 31(11), 810. Vol. 31 , No. 11 , pp. $810-818$. 11 - El-azab, D. M. : (1994), A Study through the Using of Computers in Arbitration boxing, Journal of Sports Science and Physical Education, Al-Minia University .

12 - El-Hoala , E. A. : (2006), The Effect of Developing the Reaction on Some Attention Aspects and the Accuracy of Punches Delivery for Beginners, Journal of the Service Center for Research Consulting, Menoufiya University .

13 - Hssanen, M. S. : (1987), Evaluation and Measurement in Physical Education, Dar Elfekr Al-Arabi , Cairo .

\section{4- Jakubiak, N. \& Saunders}

D. ; (2008), The Feasibility and Efficacy of Elastic Resistance Training for Improving the Velocity of the Olympic Taekwondo Turning kick, The Journal of Strength 
\& Conditioning Research , Vol. 22 , No. 4 , pp. 1194 1197 .

15 - Juan, C. C. \& Travis, N.

T. ; (2008), Effects of a Short-

Term Resistance Program

Using Elastic Bands Versus Weight Machines for Sedentary Middle- Aged Women, Journal of Strength and Conditioning Research , Vol. 22, No.5, pp. $1441-1448$ 16 - Khalifa , M. A. : (1997), The Impact of Developing the Coordinative Neuromuscular on Some Motor Skills of Boxing Youngster, Master Thesis, Physical Education Faculty, Port Said .

17- Khedr, A. F. : (1996), The Reference in Boxing, Monshat el-Maaref , Cairo.

18 - Kozub, F. M. , \& Voorhis, T. ; (2012) , Using Bands to Create TechniqueSpecific Resistance Training for Developing Explosive Power in Wrestlers, Strength \& Conditioning Journal, Vol. 34 , No. 5 , pp. $92-95$.

19- Melchiorri, G. \& Rainoldi, A.; (2011), Muscle Fatigue Induced by Two
Different Resistances : Elastic Tubing versus Weight Machines, Journal of Electromyography and Kinesiology , Vol. 21 , No. 6 , pp. $954-959$.

20 - Mohamed, A. A. : (1995), A Training Program in Boxing to Counter the Using of Computers in Arbitration, $\mathrm{PhD}$ Thesis, Physical Education Faculty, Zagazig .

21- Muthusubramanian, J. ; (2000), Effect of Elastic Strength Training on Selected Physical Fitness Variables of Novice College Men High Jumpers , International Journal of Physical Education, Fitness and Sports, Vol. 2 , No. 4 , pp. $26-28$.

22- Osman, I. H. \& Ghoneim, M. A. \& El-azab, D. M. : (1997), Learning and Training of Boxing, Dar el-Saada, Cairo 23- Radwan, M. N.: (2003), Inferential Statistics in the Science of Physical Education and Sports , Dar El-fekr AlArabi, Cairo .

24- Radwan, M. N. : (1989), Nonparametric Statistics in Assiut Journal For Sport Science Arts 
Physical Education Research, Dar El-fekr Al-Arabi, Cairo . 25- Saied, J. A., et. al. ; (2011), Electromyographic Activity and Applied Load During High Intensity Elastic Resistance and Nautilus Machine Exercises, Journal of Human Kinetics, Vol. 30 , pp. $5-12$.

25- Saied, J. A. , et . al. ; (2011), Electromyographic Activity and Applied Load During High Intensity Elastic Resistance and Nautilus Machine Exercises, Journal of Human Kinetics, Vol. 30 , pp. $5-12$.

26- Shalan, A. M. \& Ghoneim, M. A.: (1990), Identify of the Most Commonly Used Types of Punches in Boxing Match, The Scientific Journal Physical Education , Vol. 6, Physical Education Faculty of Helwan University, Cairo .
27- Stevenson, M. W. , ; (2010), Acute Effects of Elastic Bands during the FreeWeight Barbell Back Squat Exercise on Velocity, Power, and Force Production, The Journal of Strength \& Conditioning Research Vol. 24 , No. 11 , pp. 2944 - 2954 .

28- Thibaudeau , C.; (2007), Theory and Application of Modern Strength and Power Methods, Francois Lepine, San Francisco.

29- Thomas, R. B. , : (2008), Essentials of Strength Training and Conditioning , 3rd ed., Human Kinetics, Champaign . 